\title{
The first-principle study of $\mathrm{N}_{2} \mathrm{O}$ gas interaction on the surface of pristine and Si-, Ga-, SiGa-doped of armchair boron phosphide nanotube: DFT method
}

\author{
M Rezaei Sameti and Kh Hadian \\ Department of Physical Chemistry, Faculty of Science, Malayer University, Malayer, Iran \\ E-mail: mrsameti@maleru.ac.ir
}

(Received 4 January 2015 ; in final form 17 September 2016)

\begin{abstract}
In present research, the electrical, structural, quantum and NMR parameters of interaction of $\mathrm{N}_{2} \mathrm{O}$ gas on the $\mathrm{B}$ and $\mathrm{P}$ sites of pristine, Ga-, Si- and SiGa-doped $(4,4)$ armchair models of boron phosphide nanotubes (BPNTs) are investigated by using density functional theory (DFT). For this purpose, we consider seven models for adsorption of $\mathrm{N}_{2} \mathrm{O}$ gas on the exterior surfaces of BPNTs and then all structures are optimized by B3LYP level of theory and 6-31G (d) base set. The optimized structures are used to calculate the electrical, structural, quantum and NMR parameters. The computational results reveal that the adsorption energy of all studied models of BPNTs is negative values and all processes are exothermic and favorable in thermodynamic approach. When $\mathrm{N}_{2} \mathrm{O}$ gas is adsorbed from its $\mathrm{O}$ atom head on the $\mathrm{B}$ site of nanotube, $\mathrm{N}_{2} \mathrm{O}$ gas dissociated to $\mathrm{O}$ atom and $\mathrm{N}_{2}$ molecule. The adsorption energy of this process is more than those of other models and more stable than other models. In $\mathrm{A}, \mathrm{B}$ and $\mathrm{C}$ models the global hardness decrease significantly from original values and so the activity of nanotube increases from original state. On the other hand, the electrophilicity index $(\omega)$, electronic chemical potential $(\mu)$, electronegativity $(\chi)$ and global softness $(S)$ of the A, B and C models increase significantly from original value and the CSI values of the C model are larger than those of other models. The results demonstrate that the Ga-, $\mathrm{Si}$ - and $\mathrm{SiGa}-$ doped BPNTs are good candidates to adsorbing and making $\mathrm{N}_{2} \mathrm{O}$ gas sensor.
\end{abstract}

Keywords: BPNTs, NMR, $\mathrm{N}_{2} \mathrm{O}$ adsorption, Ga-, Si- and SiGa-doped, DFT

\section{Introduction}

Nitrous oxide $\left(\mathrm{N}_{2} \mathrm{O}\right)$ is a colorless, non-flammable gas, with a slightly sweet odour and taste. It is used in surgery and dentistry for its anaesthetic and analgesic effects [1]. $\mathrm{N}_{2} \mathrm{O}$ has been generated as a byproduct in nitric and adipic acids [2-5]. Environmental researches show that $\mathrm{N}_{2} \mathrm{O}$ gas is an environmental pollutant and a relatively strong greenhouse. It has an important role in the destruction of the ozone layer in the stratosphere, for this purpose, the extensive researches are carried out to adsorb and control $\mathrm{N}_{2} \mathrm{O}$ gas from stratosphere and environmental by theoretical and experimental investigations [6-15]. Baei et al. illustrate that the adsorption energy for $\mathrm{N}_{2} \mathrm{O}$ on the surface of $(6,0),(7,0)$, and $(8,0)$ zigzag models of BNNTs in O-down is a little more than that in $\mathrm{N}$-down [9-10]. Inspection of the results of Soltani et al. elucidates that with adsorbing $\mathrm{N}_{2} \mathrm{O}$ gas on the AlNNTs and AlPNTs the electronic properties of the nanotubes would be changed, and the adsorption of $\mathrm{N}_{2} \mathrm{O}$ gas on the $(6,0)$ zigzag AlNNTs is more stable than $(4,4)$ armchair model [11]. Boron phosphide nanotubes are inorganic analogs of carbon nanotubes (CNTs) and have good physical properties for a broad variety of applications. In recent years, the extensive research has been done on the structural, electrical, NMR and NQR parameters and adsorption of $\mathrm{C}_{6} \mathrm{H}_{6}, \mathrm{H}_{2} \mathrm{O}_{2}, \mathrm{CO}$ and $\mathrm{NO}$ on the surface of boron phosphide Nanotube [12-20].

Following our previous researches on the effects of Ga-, Ge-, Ge-As, Ga-As doped on the electrical, structural and NMR parameters of the armchair and zigzag models of BPNTs [21-25], in the present project, we investigate the adsorption energy, structural and electrical parameters of the nanotube $/ \mathrm{N}_{2} \mathrm{O}$ complex and the effects of $\mathrm{Si}-$, Ga- and $\mathrm{SiGa}$-doped on the $\mathrm{N}_{2} \mathrm{O}$ adsorption on the surface of $(4,4)$ armchair boron phosphide nanotube (BPNTs). The structural, NMR, NBO and quantum parameters including HOMO, LOMU orbital, energy gap, electronic chemical potential $(\mu)$, global hardness $(\eta)$, electrophilicity index $(\omega)$, energy gap $\left(\Delta E_{(g a p)}\right)$, global softness $(S)$, 


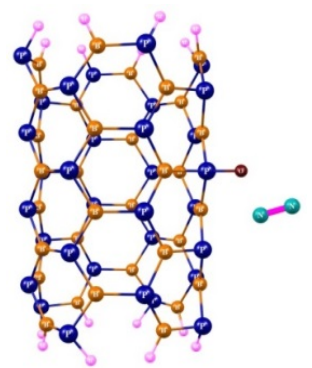

Model A

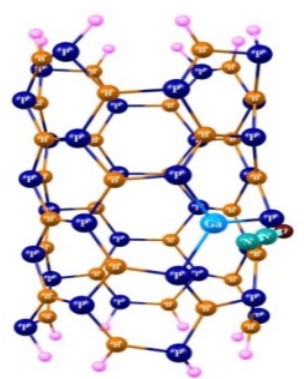

Model E

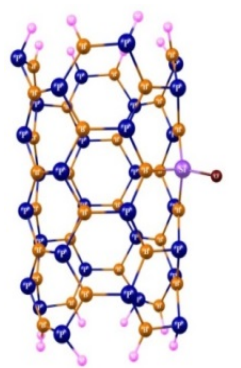

Model B

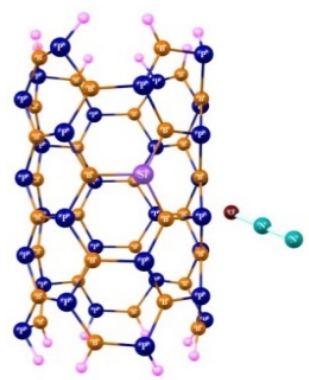

Model F

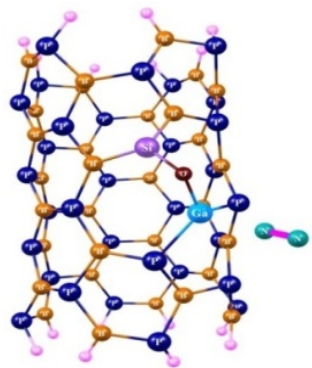

Model C

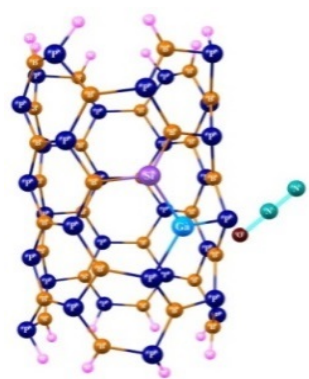

Model G

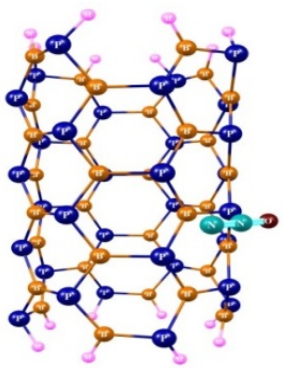

Model D

Figure 1. 2D views of $\mathrm{N}_{2} \mathrm{O}$ adsorption on the surface of $(4,4)$ armchair model BPNTs of the $(A-\mathrm{G})$ Models.

electronegativity $(\chi)$ for the all adsorption models are determined by using Gaussian 03 program package [26].

\section{Computational methods}

In the first step, all adsorption structures are allowed to relax by all atomic geometrical optimization at the B3LYP/6-31G (d) methods by using GAUSSIAN 03 program [26]. The optimized structures are used to determine adsorption energy, NMR, NBO, and quantum parameters of $\mathrm{N}_{2} \mathrm{O}$ adsorption.

The adsorption energy $\left(E_{a d s}\right)$ of $\mathrm{N}_{2} \mathrm{O}$ gas on the surface of BPNTs is calculated as follows:

$E_{a d s}=E_{B P N T s-N_{2} O}-\left(E_{B P N T s}+E_{N_{2} O}\right)$

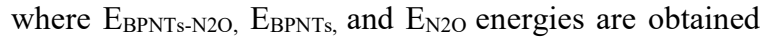
from the optimized BPNTs/ $\mathrm{N}_{2} \mathrm{O}$, BPNTs and $\mathrm{N}_{2} \mathrm{O}$ gas respectively. The quantum molecular descriptors electronic, Fermi level energy $\left(\mathrm{E}_{\mathrm{FL}}\right)$, electronic chemical potential $(\mu)$, global hardness $(\eta)$, electrophilicity index $(\omega)$, energy gap (E $\left.\mathrm{E}_{\text {gap }}\right)$, global softness $(S)$, electronegativity $(\chi)$, and work function $(\varphi)$ of the nanotubes calculated as follows [21-25]:

$\mu=-(I+A) / 2$,

$\eta=(I-A) / 2$,

$\chi=-\mu$,

$\omega=\mu^{2} / 2 \eta$,

$S=1 / 2 \eta$,

$E_{F L}=\left(E_{H O M O}+E_{L U M O}\right) / 2$,

$\varphi=E_{H O M O}-E_{F L}$,

$E_{\text {gap }}=E_{L U M O}-E_{H O M O}$,

where $I$ (- $\left.\mathrm{E}_{\text {Hомо }}\right)$ is the ionization potential and $A$ (- $\left.\mathrm{E}_{\mathrm{LUMO}}\right)$ the electron affinity of the molecule.
The chemical shielding (CS) tensors at the sites of ${ }^{11} \mathrm{~B}$, ${ }^{31} \mathrm{P}$ nuclei calculated in the principal axes system (PAS) $\left(\sigma_{33}>\sigma_{22}>\sigma_{11}\right)$ and converted to measurable NMR parameters, chemical shielding isotropic (CSI) and chemical shielding anisotropic (CSA) by using equations (9) and (10), respectively [21-25].

$$
\begin{aligned}
& \operatorname{CSI}(\text { ppm })=\frac{1}{3}\left(\sigma_{11}+\sigma_{22}+\sigma_{33}\right), \\
& \operatorname{CSA}(\text { ppm })=\sigma_{33}-\left(\sigma_{22}+\sigma_{33}\right) / 2,
\end{aligned}
$$

\section{Results and discussion}

\subsection{The optimized geometry parameters}

In order to identify the most stable configuration, we consider several potential configurations, including the $\mathrm{N}_{2} \mathrm{O}$ molecule is initially placed above pristine, $\mathrm{Si}-$, Ga-, and SiGa-doped BPNTs. After structural optimizations, re-orientation of the molecule has been predicted in some configurations, and finally, stable configurations are obtained. The stable configurations for adsorption $\mathrm{N}_{2} \mathrm{O}$ gas is renamed the $\mathrm{A}, \mathrm{B}, \mathrm{C}, \mathrm{D}, \mathrm{E}, \mathrm{F}$, and $\mathrm{G}$ models:

Adsorption of $\mathrm{N}_{2} \mathrm{O}$ gas on the $\mathrm{P} 41$ site of pristine (A model), on the P41/Si site of Si-doped (B model), on the P41/Si site of GaSi-doped (C model), on the B51 site of pristine (D model), on the B51/Ga site of Ga-doped (E model), on the B51 site of Si-doped (F model), on the $\mathrm{B} 51 / \mathrm{Ga}$ site of GaSi-doped ( $\mathrm{G}$ model), BPNTs via oxygen head and in which the ends of the nanotubes are saturated by hydrogen atoms. The final optimized geometry of the $\mathrm{N}_{2} \mathrm{O} / \mathrm{BPNT}$ complexes is depicted in

From optimized structures of the $\mathrm{A}-\mathrm{G}$ models (figure 1) the geometrics parameters, including bond length $(\mathrm{B}-\mathrm{P})$ and bond angle $(\mathrm{B}-\mathrm{P}-\mathrm{B})$ of neighbor adsorption and doping positions are determined and the 
Table 1. Structural parameters of adsorption $\mathrm{N}_{2} \mathrm{O}$ molecule on the surface pristine and $\mathrm{Si}, \mathrm{Ga}$, SiGa doped of BPNTs models (A-G see figure 1).

\begin{tabular}{|c|c|c|c|c|c|c|c|c|c|c|c|}
\hline $\begin{array}{l}\text { Bond } \\
\text { length }(\AA)\end{array}$ & Pristine & $\begin{array}{c}\text { Ga- } \\
\text { doped }\end{array}$ & $\begin{array}{c}\text { Si- } \\
\text { doped }\end{array}$ & $\begin{array}{l}\text { GaSi- } \\
\text { doped }\end{array}$ & $\begin{array}{c}\text { Model } \\
\text { A }\end{array}$ & $\begin{array}{c}\text { Model } \\
\text { B }\end{array}$ & $\begin{array}{l}\text { Model } \\
\text { C }\end{array}$ & $\begin{array}{l}\text { Model } \\
\text { D }\end{array}$ & $\begin{array}{c}\text { Model } \\
\text { E }\end{array}$ & $\begin{array}{c}\text { Model } \\
\text { F }\end{array}$ & $\begin{array}{c}\text { Model } \\
\text { G }\end{array}$ \\
\hline B31-P41/Si & 1.97 & 1.89 & 1.88 & 1.88 & 1.96 & 2.02 & 1.97 & 1.89 & 1.92 & 1.97 & 1.97 \\
\hline P52-B42 & 1.97 & 1.92 & 1.91 & 1.94 & 1.89 & 1.86 & 1.89 & 1.89 & 1.91 & 1.88 & 1.89 \\
\hline $\mathrm{B} 42-\mathrm{P} 41 / \mathrm{Si}$ & 1.88 & 1.92 & 1.91 & 1.93 & 1.97 & 2.03 & 1.96 & 1.88 & 1.91 & 1.96 & 1.97 \\
\hline $\begin{array}{l}\mathrm{P} 41 / \mathrm{Si}- \\
\mathrm{B} 51 / \mathrm{Ga}\end{array}$ & 1.92 & 2.26 & 1.87 & 2.27 & 1.96 & 2.06 & 2.24 & 1.90 & 2.26 & 1.97 & 2.30 \\
\hline B51/Ga-P61 & 1.90 & 2.25 & 1.97 & 2.29 & 1.90 & 1.89 & 2.26 & 1.89 & 2.26 & 1.88 & 2.26 \\
\hline $\mathrm{P} 51-\mathrm{B} 51 / \mathrm{Ga}$ & 1.89 & 2.25 & 1.88 & 2.25 & 1.86 & 1.86 & 2.28 & 1.88 & 2.26 & 1.88 & 2.28 \\
\hline \multicolumn{12}{|l|}{ Bond Angle $\left({ }^{\circ}\right)$} \\
\hline $\begin{array}{l}\text { B31-P41/Si- } \\
\text { B42 }\end{array}$ & 120.73 & 98.49 & 111.22 & 100.10 & 102.08 & 106.69 & 109.81 & 110.44 & 105.38 & 114.24 & 112.26 \\
\hline $\begin{array}{l}\text { B31-P41/Si- } \\
\text { B51/Ga }\end{array}$ & 121.67 & 122.83 & 118.66 & 119.46 & 118.24 & 114.31 & 111.10 & 116.69 & 107.73 & 119.63 & 113.91 \\
\hline $\begin{array}{l}\mathrm{B} 42-\mathrm{P} 41 / \mathrm{Si}- \\
\mathrm{B} 51 / \mathrm{Ga}\end{array}$ & 121.77 & 107.67 & 119.70 & 113.01 & 102.04 & 103.27 & 110.80 & 110.63 & 101.42 & 114.19 & 108.50 \\
\hline $\begin{array}{l}\text { P41/Si-B42- } \\
\text { P32 }\end{array}$ & 121.38 & 125.25 & 117.97 & 121.15 & 120.58 & 118.08 & 110.90 & 121.76 & 117.47 & 119.26 & 115.63 \\
\hline $\begin{array}{l}\mathrm{P} 41 / \mathrm{Si}- \\
\mathrm{B} 51 / \mathrm{Ga}-\mathrm{P} 61\end{array}$ & 120.76 & 100.08 & 114.23 & 107.18 & 114.40 & 115.38 & 114.02 & 116.43 & 113.25 & 117.30 & 115.28 \\
\hline $\begin{array}{l}\text { B51/Ga-P61- } \\
\text { B62 }\end{array}$ & 120.55 & 113.13 & 117.41 & 115.38 & 106.38 & 108.94 & 112.10 & 111.13 & 101.57 & 112.31 & 104.95 \\
\hline
\end{tabular}

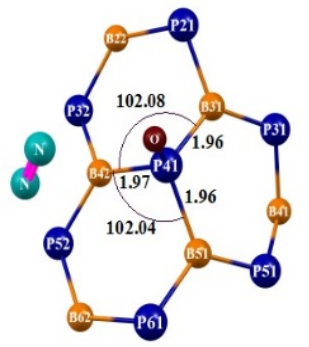

Model A

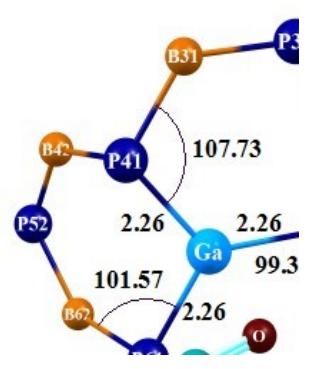

Model E

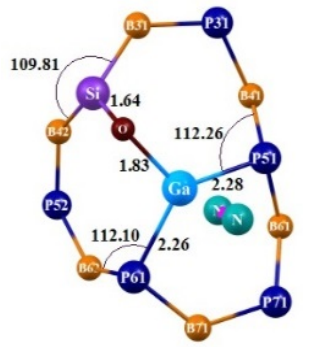

Model B

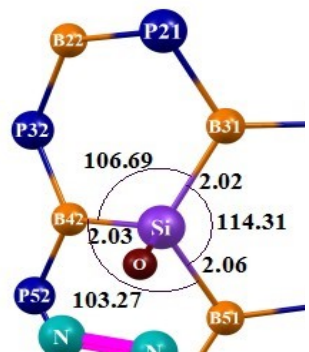

Model C

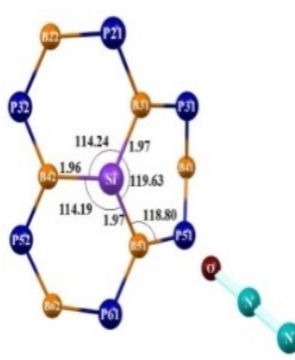

Model F

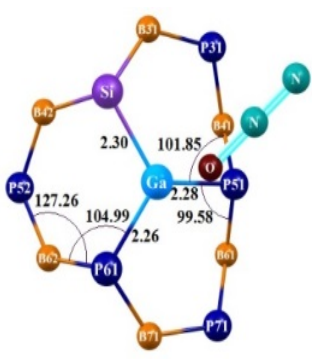

Model G

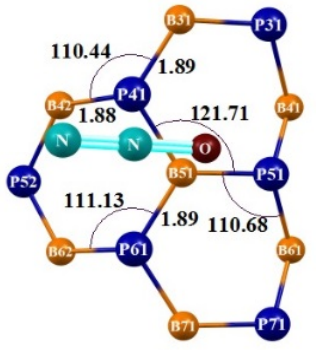

Model D

Figure 2. 2D views of bond length and bond angle of around $\mathrm{N}_{2} \mathrm{O}$ adsorption and doping position of the (A-G) Models (see figure 1).

results are given in table 1 and shown in figure 2 . The geometrical results show that the average bond length $\mathrm{B}-\mathrm{P}$ and bond angle $\mathrm{B}-\mathrm{P}-\mathrm{B}$ of pristine BPNTs are 1.89 $\mathrm{A}$ and $121.40^{\circ}$ respectively, which are in agreement with the previous results reported by other researchers [1720, 26-29]. With doping Si on the P41 nuclei, the bond length and bond angle of around doping position change slightly from those of pristine models. Moreover with doping $\mathrm{Ga}$ on the B51 nuclei, the average bond length increases significantly from 1.89 to $2.25 \AA$ and the bond angle decreases significantly from 121.40 to $107.67^{\circ}$. When Si and $\mathrm{Ga}$ atoms are doped together on the P41 nuclei and B51 nuclei the average bond length increases significantly from 1.89 to $2.29 \AA$ and the bond angle decreases significantly from 121.77 to $113.67^{\circ}$. The radius of $\mathrm{Ga}$ atom is larger than that of $\mathrm{B}$ atom, and so Ga doping in nanotube distributes the charge electron 
Table 2. Quantum parameters of $\mathrm{N}_{2} \mathrm{O}$ adsorption on the surface of $(4,4)$ armchair BPNTs (models $\mathrm{A}-\mathrm{G}$ figure 1 ).

\begin{tabular}{|c|c|c|c|c|c|c|c|c|c|c|c|}
\hline Property & Pristine & $\begin{array}{c}\text { Si- } \\
\text { doped }\end{array}$ & $\begin{array}{c}\text { Ga- } \\
\text { doped }\end{array}$ & $\begin{array}{l}\text { GaSi- } \\
\text { doped }\end{array}$ & $\begin{array}{c}\text { Model } \\
\text { A }\end{array}$ & $\begin{array}{c}\text { Model } \\
\text { B }\end{array}$ & $\begin{array}{c}\text { Model } \\
\text { C }\end{array}$ & $\begin{array}{c}\text { Model } \\
\text { D }\end{array}$ & $\begin{array}{c}\text { Model } \\
\text { E }\end{array}$ & $\begin{array}{c}\text { Model } \\
\text { F }\end{array}$ & $\begin{array}{c}\text { Model } \\
\text { G }\end{array}$ \\
\hline $\begin{array}{l}\text { Eads/kcal } \\
\mathrm{mol}^{-1}\end{array}$ & - & - & - & - & -35.459 & -45.589 & -66.005 & -0.449 & -4.602 & -0.617 & -5.488 \\
\hline $\mathrm{E}_{\text {номо }} / \mathrm{eV}$ & -5.864 & -5.489 & -5.878 & -5.649 & -5.967 & -5.918 & -7.282 & -5.867 & -5.850 & -5.461 & -5.592 \\
\hline $\mathrm{E}_{\mathrm{LUMO}} / \mathrm{eV}$ & -2.901 & -2.925 & -2.966 & -2.925 & -3.431 & -3.320 & -5.056 & -2.903 & -2.917 & -2.865 & -2.876 \\
\hline $\mathrm{E}_{\mathrm{gap}} / \mathrm{eV}$ & 2.963 & 2.610 & 2.912 & 2.724 & 2.536 & 2.599 & 2.226 & 2.963 & 2.933 & 2.596 & 2.716 \\
\hline $\mathrm{I} / \mathrm{eV}$ & 5.864 & 5.489 & 5.878 & 5.649 & 5.967 & 5.918 & 7.282 & 5.867 & 5.850 & 5.461 & 5.592 \\
\hline $\mathrm{A} / \mathrm{eV}$ & 2.901 & 2.879 & 2.966 & 2.925 & 3.431 & 3.320 & 5.056 & 2.903 & 2.917 & 2.865 & 2.876 \\
\hline$\eta / \mathrm{eV}$ & 1.482 & 1.305 & 1.456 & 1.362 & 1.268 & 1.299 & 1.113 & 1.482 & 1.467 & 1.298 & 1.358 \\
\hline$\mu / \mathrm{eV}$ & -4.382 & -4.184 & -4.422 & -4.287 & -4.699 & -4.619 & -6.169 & -4.385 & -4.384 & -4.163 & -4.234 \\
\hline $\mathrm{S} / \mathrm{eV}$ & 0.337 & 0.383 & 0.343 & 0.367 & 0.394 & 0.385 & 0.449 & 0.337 & 0.341 & 0.385 & 0.368 \\
\hline$\omega / \mathrm{eV}$ & 6.481 & 6.708 & 6.715 & 6.748 & 8.708 & 8.210 & 17.096 & 6.489 & 6.551 & 6.677 & 6.601 \\
\hline$\chi / \mathrm{eV}$ & 4.382 & 4.184 & 4.422 & 4.287 & 4.699 & 4.619 & 6.169 & 4.385 & 4.384 & 4.163 & 4.234 \\
\hline$\tilde{E}_{\mathrm{FL}} / \mathrm{ev}$ & -4.382 & -4.184 & -4.422 & -4.287 & -4.699 & -4.619 & -6.169 & -4.385 & -4.384 & -4.163 & -4.234 \\
\hline$\phi / e V$ & -1.482 & -1.305 & -1.450 & -1.362 & -1.268 & -1.299 & -1.113 & -1.482 & -1.467 & -1.298 & -1.358 \\
\hline$\Delta \rho(\mathrm{NBO})$ & - & - & - & - & -1.033 & -0.723 & -1.090 & 0.003 & 0.048 & 0.004 & 0.060 \\
\hline $\begin{array}{l}\text { Dipole } \\
\text { moment }\end{array}$ & 0.002 & 0.317 & 0.065 & 0.812 & 4.385 & 3.324 & 1.561 & 0.095 & 1.291 & 0.714 & 2.061 \\
\hline
\end{tabular}

density around doping position and so the bond length and bond angle of Ga-doped model change considerably compared to the pristine model.

To study the adsorption of $\mathrm{N}_{2} \mathrm{O}$ gas on the surface of BPNTs, we investigate the interaction of $\mathrm{N}_{2} \mathrm{O}$ gas with $\mathrm{O}$-site on the surface of nanotube. Since oxygen atom is more electronegative than nitrogen atom, for configuration, in which oxygen atom orients toward the BPNTs surfaces, the interaction between $\mathrm{N}_{2} \mathrm{O}$ gas and surfaces of nanotube is more than other orientations. For this purpose, we consider two different configurations for adsorption of $\mathrm{N}_{2} \mathrm{O}$ gas on the surface of nanotube: (1) The adsorption of $\mathrm{N}_{2} \mathrm{O}$ gas on the nonmetal site of nanotube (see the A-C models Fig. 1), (2) the adsorption of $\mathrm{N}_{2} \mathrm{O}$ gas on the metal site of nanotube (see the $\mathrm{D}-\mathrm{G}$ models Fig. 1).

The optimized configurations of $\mathrm{N}_{2} \mathrm{O}$ adsorption on the surface of BPNTs in figure 1 show that, when $\mathrm{N}_{2} \mathrm{O}$ gas localizes on the metal site, the $\mathrm{N}_{2} \mathrm{O}$ gas is gradually bent inward, away from the $\mathrm{B}$ atom and the adsorption of $\mathrm{N}_{2} \mathrm{O}$ is in molecule form on the horizontal surface of nanotube. For this means the bond length $(\mathrm{B}-\mathrm{P})$ and bond angle $(\mathrm{B}-\mathrm{P}-\mathrm{B})$ of the $(\mathrm{D}-\mathrm{G})$ models, change slightly from original values due to physisorption of $\mathrm{N}_{2} \mathrm{O}$ (see Fig. 2). When $\mathrm{N}_{2} \mathrm{O}$ gas localizes on the nonmetal site, it is dissociated to $\mathrm{O}$ atom which is adsorbed on nonmetal nuclei and $\mathrm{N}_{2}$ molecule which is formed on the parallel surface of the nanotube.

Therefore, the bond length $(\mathrm{B}-\mathrm{P})$ around the adsorption position in the $(\mathrm{A}-\mathrm{C})$ models increases slightly from pure models and the bond angle $(\mathrm{B}-\mathrm{P}-\mathrm{B})$ decreases significantly from those of pure models (see Fig. 2).

The adsorption energy ( $\left.E_{a d s}\right)$ of the $A-G$ models is calculated by using Eqs. 1 and the results are given in table 2 of supplementary data and are shown in figure 3 . The results of figure 3 indicate that the adsorption energy of all models is negative and all adsorption processes are exothermic in thermodynamic approach. The results show that the adsorption of $\mathrm{N}_{2} \mathrm{O}$ gas at the $\mathrm{A}-\mathrm{C}$ models is in chemisorption form due to dissociation of $\mathrm{O}$ atom from $\mathrm{N}_{2} \mathrm{O}$ gas and the strong adsorption of $\mathrm{O}$ atom on the surface of nanotube. Therefore, the adsorption energy of the $\mathrm{A}-\mathrm{C}$ models is in range from -35.46 to $-66.01 \mathrm{Kcal} / \mathrm{mol}$ and is more than those of the other models. On the other hand, the low energy gain from adsorption of $\mathrm{N}_{2} \mathrm{O}$ gas at the $\mathrm{D}-\mathrm{G}$ models is in range from -0.45 to $-5.49 \mathrm{Kcal} / \mathrm{mol}$ indicating that the chemical interaction between the $\mathrm{N}_{2} \mathrm{O}$ gas and BPNTs is weak and its bond character is physisorption (see Fig. 3).

The results show that the adsorption energy of the $\mathrm{C}$ model is more than those of other models and the adsorption energy of the D model is lower than those of other models. It is notable that in the pristine model of BPNTs, the adsorption of $\mathrm{N}_{2} \mathrm{O}$ gas on the $\mathrm{P}$ site of nanotube (A model) is more favorable than $\mathrm{B}$ site of nanotube (D model). The comparison results indicate that doping of $\mathrm{Si}, \mathrm{Ga}$ and $\mathrm{GaSi}$ increase the adsorption of $\mathrm{N}_{2} \mathrm{O}$ gas on the surface of nanotube. The effect of $\mathrm{GaSi}$ dopant on the adsorption of $\mathrm{N}_{2} \mathrm{O}$ gas is more than $\mathrm{Ga}$ and $\mathrm{Si}$ dopants and so the $\mathrm{C}$ model is the most stable configuration.

\section{2 Quantum molecular descriptors}

To further study the adsorption properties of $\mathrm{N}_{2} \mathrm{O}$ gas on the surface of pristine, Ga-, Si- and $\mathrm{GaSi}-$ doped boron phosphide nanotube, we investigate the highest occupied molecular orbital (HOMO) and the lowest unoccupied molecular orbital (LUMO). The HOMO and LUMO structures are calculated by DFT method and are shown in figure 4 . The comparison results of figure 4 reveal that, the HOMO orbitals of the A, B, D and E models and the LUMO orbitals of the C, D, E, F and G models are distributed uniformly throughout on the center of the nanotube axis, which illustrates that covalent functionalization is preferable throughout the nanotubes. On the other hand, the HOMO orbitals of the $\mathrm{C}, \mathrm{F}$ and $\mathrm{G}$ models and the LUMO orbitals of the A and B models distribute around adsorption position. The results reveal that in all the models the HOMO orbitals are localized on the nitrogen atoms and LUMO is more localized on $\mathrm{B}-\mathrm{P}$ bonds at the center of nanotube. 


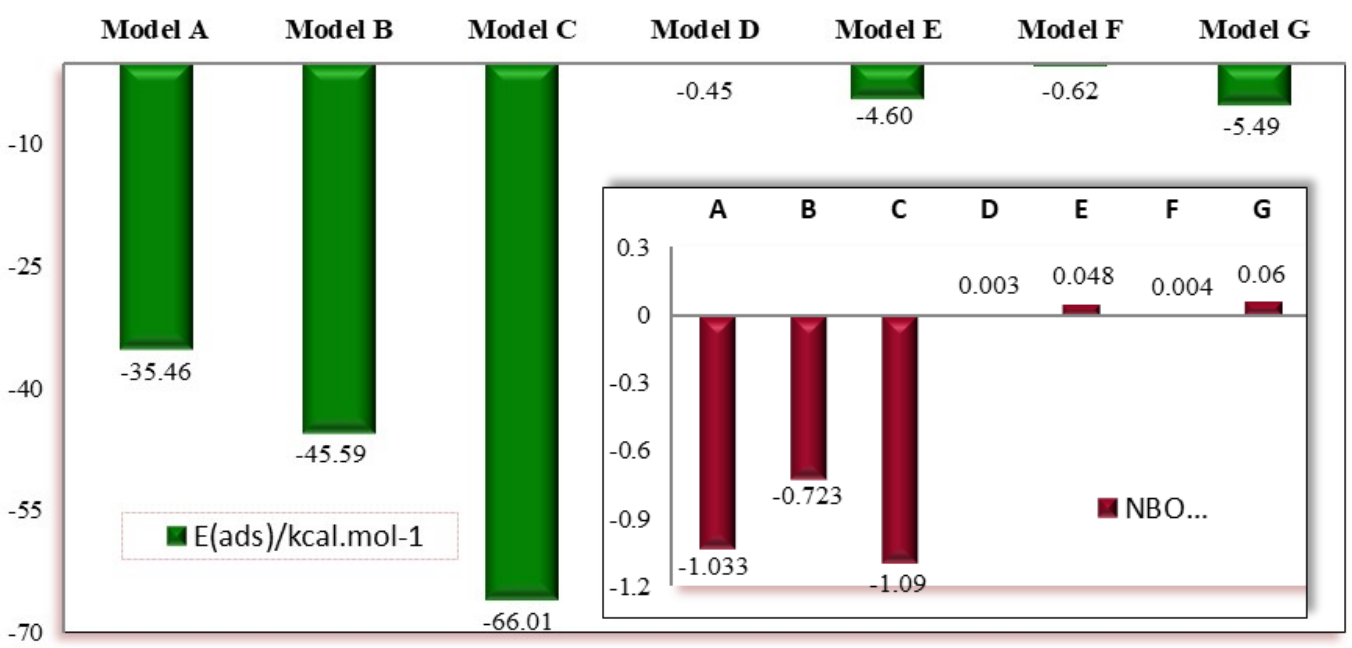

Figure 3. The plots of $\mathrm{N}_{2} \mathrm{O}$ adsorption energy and $\Delta \rho \mathrm{NBO}$ charge transfer of the (A-G) Models (see figure 1).

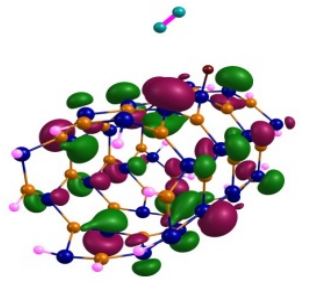

Model A-1

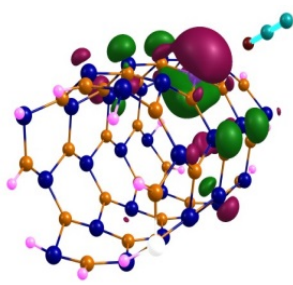

Model F-1

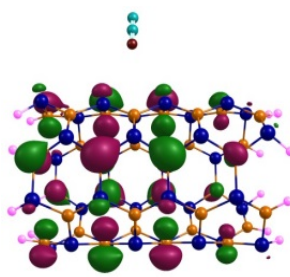

Model D-2

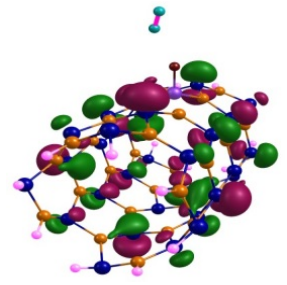

Model B-1

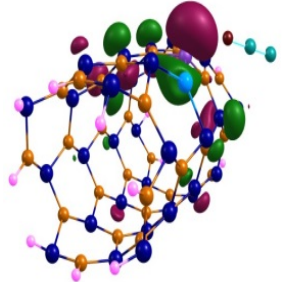

Model G-1

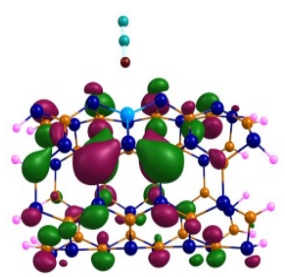

Model E-2

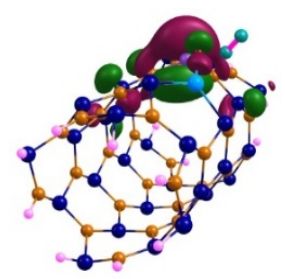

Model C-1

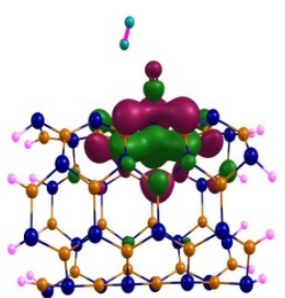

Model A-2

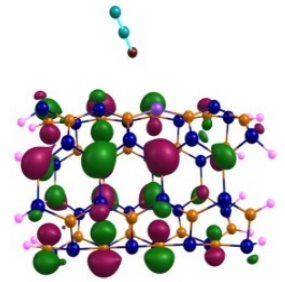

Model F-2

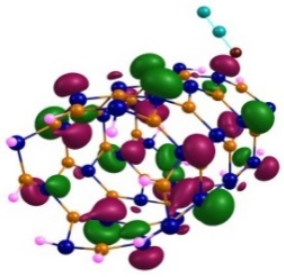

Model D-1

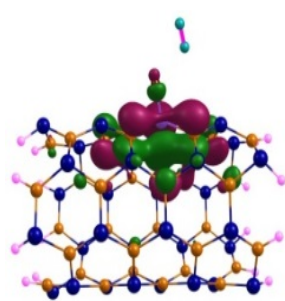

Model B-2

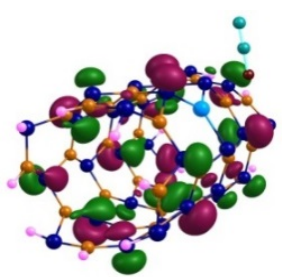

Model E-1

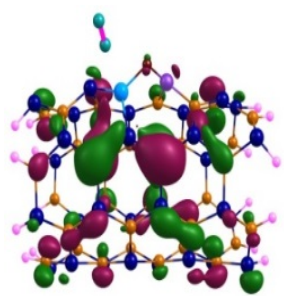

Model C-2

Figure 4 HOMO-LUMO structures of $\mathrm{N}_{2} \mathrm{O}$ adsorption on the surface of $(4,4)$ armchair model of BPNTs the (A-G) Models, index (1) used for HOMO and index (2) for LUMO (see figure 1).

From the $\mathrm{E}_{\text {HOMO }}$ and $\mathrm{E}_{\mathrm{Lumo}}$ energies the quantum molecular descriptor parameters including Fermi level energy $\left(\mathrm{E}_{\mathrm{FL}}\right)$, chemical potential $(\mu)$, global hardness $(\eta)$, electrophilicity index $(\omega)$, energy gap $\left(\Delta \mathrm{E}_{\text {gap }}\right)$, global softness $(S)$, electronegativity $(\chi)$ and work function $(\varphi)$ of the nanotubes are calculated by eqs. (2-9) and the results are given in table 2 of supplementary data and figures (5-7). Inspection of the calculated results 
Model A Model B Model C ModelD ModelE ModelF Model G

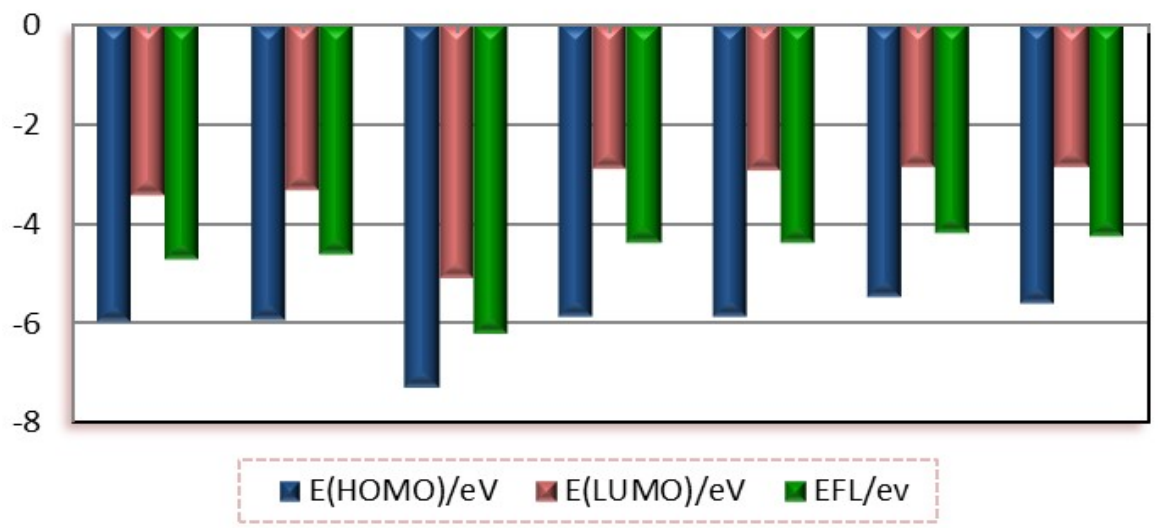

Figure 5. The plots of HOMO, LUMO and Fermi level energy of the (A-G) Models (see figure 1).

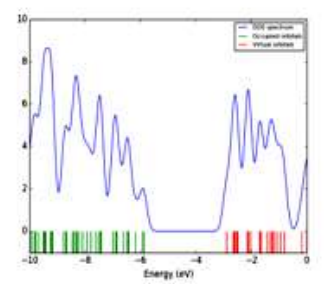

a

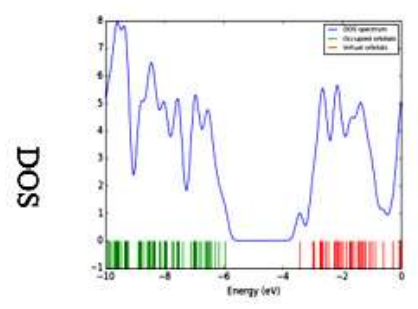

Model A

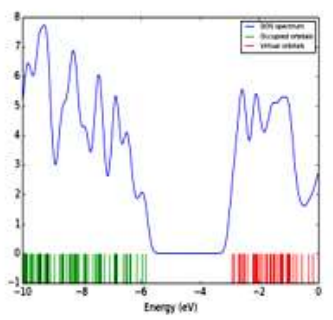

Model E

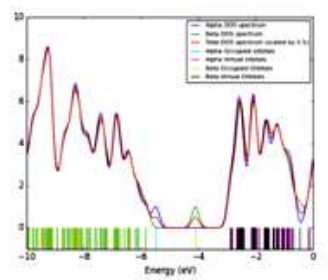

b

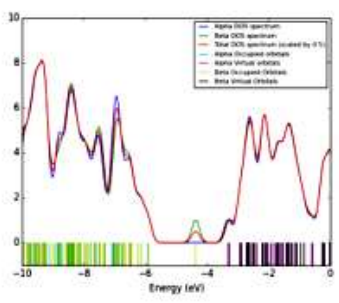

Model B

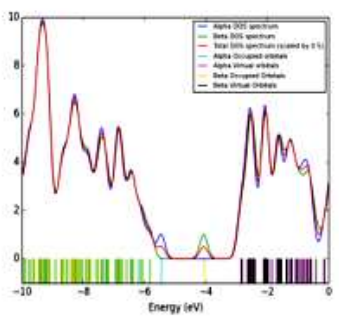

Model F

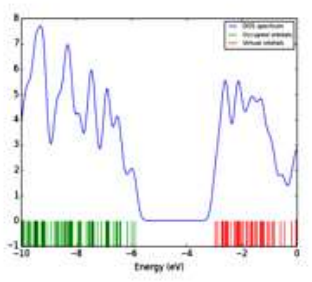

c

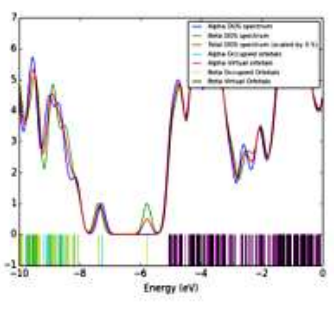

Model C

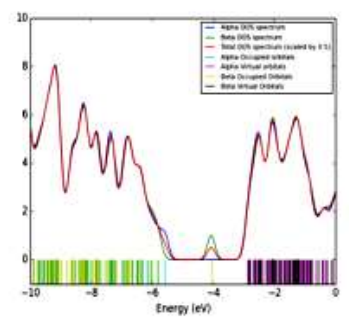

Model G

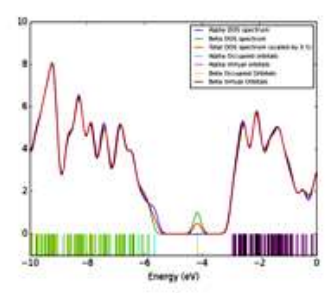

d

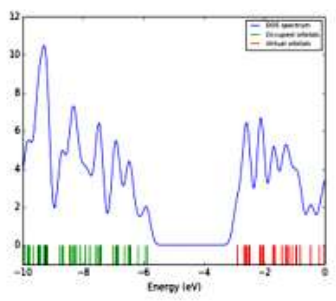

Model D

Figure 6. The plots of density of state (DOS) spectrum of the (A-G) Models (see figure 1).

indicate that, with adsorption of $\mathrm{N}_{2} \mathrm{O}$ gas on the pristine, $\mathrm{Si}, \mathrm{Ga}$ and $\mathrm{GaSi}$-doped BPNTs surface, the $\mathrm{E}_{\text {Hомо }}$ and $\mathrm{E}_{\mathrm{LUMO}}$ energies for the A-E models are decreased from pure nanotube, therefore both groups of occupied and unoccupied molecular orbital are more stable than those for BPNTs. Furthermore, $\mathrm{E}_{\mathrm{HOMO}}$ and $\mathrm{E}_{\mathrm{LUMO}}$ energies for the $F$ and $G$ models are increased slightly from pure nanotube.

The Fermi level energy is the total chemical potential for electrons (or electrochemical potential for electrons) and is used to determine the thermodynamic work required to add one electron to the system (not counting the work required to remove the electron from wherever it came). A precise understanding of the Fermi energy level can relate the electronic band structure with the electronic properties of nanotube. Figure 5 reveals that the Fermi level energy of all the models is toward $\mathrm{E}_{\text {номо }}$ and is in the range from -4.234 to $-6.169 \mathrm{eV}$. The comparison results show that the Fermi level energy of the $\mathrm{C}$ model is larger than other models and that of the $\mathrm{G}$ model is lower than those of other models. The location of the Fermi level energy relative to the $\mathrm{E}_{\text {HOMO }}$ is probably the most important factor in determining the current, and understanding it assists in determining the 


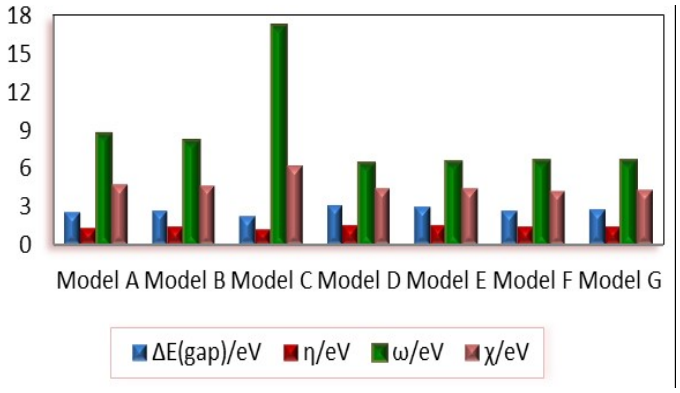

Figure 7. The plots of energy gap ( $\left.\mathrm{E}_{\mathrm{gap}}\right)$, global hardness $(\eta)$, electrophilicity index $(\omega)$, electronegativity $(\chi)$ of the $(A-G)$ Models (see Figure 1).

direction of natural flow of electrons where the two materials are joined. Therefore, knowing this has significant practical applications.

Energy gap $\left(\mathrm{E}_{\mathrm{gap}}\right)$ is a significant parameter which is used to determine the chemical activity and semiconductivity of the nanotube. A small value for energy gap means a high chemical activity and semiconductivity of the nanotube. The calculated energy gap of unabsorbed and adsorbed models of BPNTs are given in table 2 of supplementary data and shown in figure 7. The comparison results show that the energy gap for pristine, $\mathrm{Si}, \mathrm{Ga}$, SiGa-doped of unabsorbed BPNTs is in the range from 2.610 to $2.963 \mathrm{eV}$. The results show that the energy gap of Si doped is lower than pristine, and so the chemical activity of $\mathrm{Si}$-doped BPNTs is higher than other pristine.

The results indicate that, with doping $\mathrm{Si}, \mathrm{Ga}$ and $\mathrm{SiGa}$ the gap energy reduces slightly from pristine models and so their electrical conductance of doped models increases from pristine model. When $\mathrm{N}_{2} \mathrm{O}$ gas adsorb on the surface of BPNTs in the A, B and C models the energy gap reduce from original values thus, the chemical activity of these models will be slightly increase, and in the other models the energy gap is slightly constant.

One of the important physical properties of nanomaterial in solid state is density of state (DOS) spectrum. The density of states (DOS) spectrum of a system describes the number of states per interval of energy at each energy level that are available to be occupied. A high DOS at a specific energy level means that there are many states available for occupation. In this work by using GaussSum program [30] the density of states (DOS) of spectrum has been obtained from the output of HOMO and LUMO calculations for BPNTs before and after $\mathrm{N}_{2} \mathrm{O}$ adsorption and is shown in figure 6 .

The results of figure 6 reveal that the DOS spectrum in the pure BPNTs has six peaks in the HOMO region and four peaks in the LUMO region in the energy range from -10 to $0 \mathrm{eV}$. In $\mathrm{Si}$, and $\mathrm{SiGa}-$ doped BPNTS, we found that the DOS spectrum split two alpha and beta spectra and also in the range from -5.8 and $-4 \mathrm{eV}$ two small peaks are shown. But in the $\mathrm{Ga}-$ doped BPNTs the DOS spectrum is similar to pristine form and Ga doping

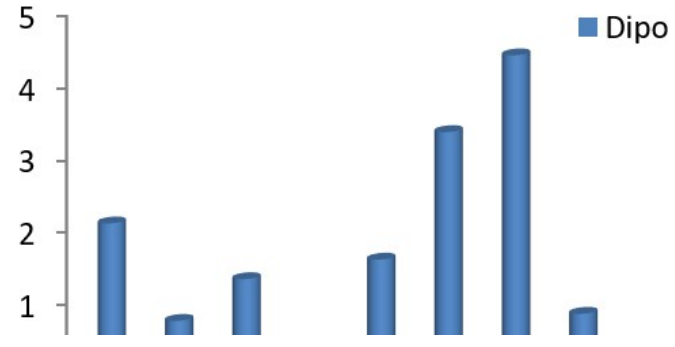

Figure 8. The plots of dipole moment of the unabsorbed $\mathrm{N}_{2} \mathrm{O}$ (models a, b, c, and d) and the (A-G) Models (see figure 1).

slightly reduces the energy gap and height peak in the LUMO region. It can be seen that the DOS spectrum of $\mathrm{N}_{2} \mathrm{O}$ adsorption on the surface of pristine, Si-, Ga-, and $\mathrm{SiGa}$-doped BPNTs displays more reasonable changes than the DOS of the pure BPNTs, revealing the slight effect of $\mathrm{N}_{2} \mathrm{O}$ gas on the electronic conductivity of BPNTs. The results exhibit that the slight difference of the DOS spectrum is shown between the $A-G$ models and the $\mathrm{a}-\mathrm{d}$ models. These results show that after the adsorption of $\mathrm{N}_{2} \mathrm{O}$ on the surface of BPNTs (A-G models), the HOMO-LUMO energy gap of nanotubes has a notable alter. This is an evidence of the interaction between $\mathrm{N}_{2} \mathrm{O}$ and BPNTs. The comparison of DOS spectrum before and after adsorption of $\mathrm{N}_{2} \mathrm{O}$ shows that the height of all the DOS peaks in the HOMO and LUMO region of $\mathrm{N}_{2} \mathrm{O}$ adsorption reduced slightly from pure nanotubes. In addition, the number of DOS peaks of the $\mathrm{A}-\mathrm{C}$ models is lower than the a-c pure models, due to chemical adsorption of $\mathrm{N}_{2} \mathrm{O}$ gas on the surface of BPNTs and dissociation of $\mathrm{O}$ atom from $\mathrm{N}_{2} \mathrm{O}$. On the other hand, the number of DOS peaks in the $D-G$ models before and after $\mathrm{N}_{2} \mathrm{O}$ adsorption is constant and the height of all the DOS peaks changes slightly. This result demonstrates that the chemical adsorptions of $\mathrm{N}_{2} \mathrm{O}$ gas changes the electrical properties of nanotube significantly and the variation of these properties is useful in industrial applications.

To better understand the nature of the interaction between $\mathrm{N}_{2} \mathrm{O}$ and BPNTs, we study the influence of $\mathrm{N}_{2} \mathrm{O}$ adsorptions on other quantum properties involving: chemical potential $(\mu)$, global hardness $(\eta)$, electrophilicity index $(\omega)$, electronegativity $(\chi)$ and work function $(\varphi)$. The calculated results are given in table 2 and shown in figure 7.

The calculated results show that the global hardness $(\eta)$ of pure BPNTs is $1.482 \mathrm{eV}$ and with doping $\mathrm{Si}, \mathrm{Ga}$ and $\mathrm{SiGa}$ decrease to $1.305,1.456$ and 1.362, respectively. Decreasing global hardness leads to decrease in stability and increase in reactivity of the species. When $\mathrm{N}_{2} \mathrm{O}$ gas is adsorbed on the surface of BPNTs in the A, B and C models, the global hardness decreases significantly from pure values. On the other hand, the electrophilicity index $(\omega)$, electronic chemical potential $(\mu)$, electronegativity $(\chi)$ and global softness $(S)$ 
of the A, B and C models increase significantly from pure BPNTs. Therefore, the comparison results confirm that chemical adsorption of $\mathrm{N}_{2} \mathrm{O}$ gas on the surface of BPNTs decreases the stability of nanotube and increases the reactivity of nanotubes. Increasing electronic chemical potentials and electronegativity of nanotube reveal that a slight charge transfer to the nanotube could occur and their electronic transport properties could be slightly changed upon adsorptions of $\mathrm{N}_{2} \mathrm{O}$. In thermodynamic approach, the direction of charge transfer is from higher chemical potential to lower electronic chemical potential, until the electronic chemical potentials become identical. Therefore, the comparison results of electronic chemical potentials and electronegativity of the $\mathrm{A}-\mathrm{C}$ models clarify that the charge transfer occurs from a definite occupied orbital in an $\mathrm{O}$ atom of $\mathrm{N}_{2} \mathrm{O}$ gas to a definite empty orbital in BPNTs. On the other hand, the electrophilicity index determines the maximum flow of electron from donor to acceptor species and supplies data connected to structural stability, reactivity and toxicity of chemical species.

The work function is a minimum energy needed to remove an electron from a solid to a point in the vacuum immediately outside the solid surface. The calculated results describe that the work function $(\varphi)$ of the $\mathrm{A}-\mathrm{C}$ models decreases significantly from pure nanotube. According to Richardson's law the emitted current density (per unit area of emitter), $J_{\mathrm{e}}\left(\mathrm{A} / \mathrm{m}^{2}\right)$, is related to the absolute temperature $T_{\mathrm{e}}$ of the emitter by the following equation:

$J_{e}=A T^{2} e^{-\phi / K T}$,

where $(A)$ is a Richardson type constant. With decreasing work function, the emitted current density of nanotube decreases. Among theoretical methods, NBO analysis [31] is a unique approach to the evaluation of the atomic and molecular charges. To study the charge transfer between $\mathrm{N}_{2} \mathrm{O}$ gas and nanotube, the charge concentration $(\Delta \rho)$ is calculated from the difference between $\mathrm{N}_{2} \mathrm{O}$ gas after adsorption and an isolated $\mathrm{N}_{2} \mathrm{O}$. The calculated NBO results are given in figure 3 . The negative values of $\Delta \rho$ for the $\mathrm{A}, \mathrm{B}, \mathrm{C}$ models demonstrate that $\mathrm{N}_{2} \mathrm{O}$ gas is an acceptor of electron species. The $\Delta \rho$ values for other models are positive, among all the models, $\mathrm{C}$ and $\mathrm{D}$ models have the largest and smallest amount of charge transfer respectively. According to obtain results, (Fig 3 and 7), the trend of adsorption energy, the electrophilicity index $(\omega)$ and NBO charge in all the models are similar. In $\mathrm{C}$ model, the values of NBO charge, adsorption energy, and the electrophilicity index are larger than those of other models.

On the other hand, when $\mathrm{N}_{2} \mathrm{O}$ gas is adsorbed on the surface of BPNTs the dipole moment of nanotube changes significantly from unabsorbed nanotube forms. From inspection of the results of figure 8 , it can be observed that the dipole moment of A and B models are larger than those of the other models. It is notable that doping a foreign impurity and adsorbed $\mathrm{N}_{2} \mathrm{O}$ gas causes the dipole moment of nanotube to change significantly from pristine models, due to charge electrons distribution of nanotube and it is important for detecting electrical properties of nanotube.

\subsection{NMR parameters of $\mathrm{N}_{2} \mathrm{O}$ adsorption on BPNTs}

The NMR parameters of ${ }^{11} \mathrm{~B}$ and ${ }^{31} \mathrm{P}$ sites for adsorption of $\mathrm{N}_{2} \mathrm{O}$ gas on the surface of pristine, Si-, Ga- and $\mathrm{SiGa}-$ doped of BPNTs A-G models are summarized in tables 3 and 4, and the plots of CSI parameters are shown in figure 9. In our previous work [21-24], it was showed that in the pristine model of BPNTs, the NMR parameters were separated into four layers, which means that the CS parameters for the atoms of each layer have equivalent chemical environment and electrostatic properties. When $\mathrm{N}_{2} \mathrm{O}$ gas is adsorbed on the surface of BPNTs, the CSI values in the $\mathrm{A}-\mathrm{B}$ models change significantly from pure nanotube, due to chemical adsorption of $\mathrm{N}_{2} \mathrm{O}$ gas and dissociation of $\mathrm{O}$ from $\mathrm{N}_{2} \mathrm{O}$ molecule. On the other hand, the CSI values of the $\mathrm{D}^{-} \mathrm{G}$ models change slightly from original values due to physical adsorption of $\mathrm{N}_{2} \mathrm{O}$ gas. The NMR parameters of various $\mathrm{B}$ atoms in $\mathrm{Ga}$, and $\mathrm{SiGa}-$ doped BPNTs show some significant changes in boron nuclei directly bonded to $\mathrm{Ga}$ atom. Hence, both the CSI and CSA parameters show important changes due to $\mathrm{Ga}$, and $\mathrm{SiGa}$ doping. Among the $\mathrm{P}$ atoms of BPNTs, in comparison with the pristine model, the greatest changes in the NMR parameters are observed for P41, P51, P61 atoms, and both CSI and CSA parameters show significant changes which are due to the substitution of $\mathrm{Ga}$ atoms. The CSI values of $\mathrm{B} 52$ site of $\mathrm{Si}$ doped models increase significantly from original values, on the other hand the CSI values of the B71 site decrease significantly from original values. According to the calculate results as shown figures 9 and 10 , the CSI values for $\mathrm{B}$ nuclei on the B32, B42, B52 and B62 atoms of the A, C, D, E, F and $G$ models are larger than those of the other atoms. The comparison results show that the CSI values at the B42 atoms of the $\mathrm{C}$ model are larger than those of the other models. Moreover, the CSI values of the B model at the B42 and B52 atoms are lower than those of other models.

The CSI values of P22, P51, and P61atoms of the A, $\mathrm{B}, \mathrm{D}, \mathrm{E}, \mathrm{F}$ and $\mathrm{G}$ models are larger than those of other atoms. The CSI trend of P22, P51 and P61 nuclei for B, $\mathrm{C}$ and $\mathrm{G}$ models is: $\mathrm{C}$ model $>\mathrm{B}$ model $>\mathrm{G}$ model. These results confirm that, the adsorption of $\mathrm{N}_{2} \mathrm{O}$ gas increases the density of electron on $\mathrm{P}$ atoms around adsorption position. This trend is in agreement with the change in the gap energy of adsorption models in comparison with pure BPNTs. Increasing CSI values decrease gap energy and increase the activity of nanotube.

\section{Conclusions}

In this project, the interaction of $\mathrm{N}_{2} \mathrm{O}$ gas on the surface of pristine, $\mathrm{Ga}-, \mathrm{Si}-$ and $\mathrm{SiGa}-$ doped on the $(4,4)$ armchair models of BPNTs is investigated by using density functional theory. For this purpose, we studied adsorption of $\mathrm{N}_{2} \mathrm{O}$ gas from $\mathrm{O}$ head on the $\mathrm{B}$ and $\mathrm{P}$ atoms of nanotube. The comparison of the results 
Table 3. NMR parameters for adsorption $\mathrm{N}_{2} \mathrm{O}$ on the surface of $(4,4)$ armchair BPNTs (models $\mathrm{A}-\mathrm{C}$ figure 1).

\begin{tabular}{|c|c|c|c|c|c|c|}
\hline \multirow{2}{*}{ Nuclei } & \multicolumn{3}{|c|}{ CSI } & \multicolumn{3}{|c|}{ CSA } \\
\hline & Model A & Model B & Model C & Model A & Model B & Model C \\
\hline P11 & 413 & 410 & 410 & 117 & 117 & 124 \\
\hline P12 & 403 & 404 & 400 & 92 & 103 & 118 \\
\hline $\mathrm{P} 21$ & 376 & 346 & 350 & 223 & 215 & 170 \\
\hline P22 & 358 & 358 & 381 & 215 & 221 & 176 \\
\hline P31 & 354 & 340 & 349 & 160 & 169 & 131 \\
\hline P32 & 331 & 315 & 313 & 126 & 105 & 204 \\
\hline $\mathrm{P} 41 / \mathrm{Si}$ & 381 & 338 & 280 & 239 & 27 & 52 \\
\hline P42 & 354 & 349 & 367 & 217 & 228 & 212 \\
\hline P51 & 358 & 338 & 429 & 164 & 189 & 70 \\
\hline P52 & 331 & 329 & 356 & 142 & 122 & 168 \\
\hline P61 & 373 & 348 & 453 & 216 & 223 & 108 \\
\hline P62 & 355 & 355 & 351 & 223 & 227 & 211 \\
\hline P71 & 355 & 354 & 385 & 173 & 163 & 104 \\
\hline P72 & 352 & 348 & 349 & 116 & 116 & 151 \\
\hline P81 & 417 & 418 & 409 & 107 & 115 & 68 \\
\hline P82 & 413 & 414 & 423 & 109 & 113 & 114 \\
\hline B11 & 33 & 34 & 37 & 103 & 95 & 144 \\
\hline B12 & 40 & 39 & 35 & 101 & 103 & 134 \\
\hline B21 & 39 & 39 & 37 & 114 & 116 & 53 \\
\hline B22 & 40 & 39 & 39 & 90 & 98 & 36 \\
\hline B31 & 36 & 30 & 39 & 77 & 90 & 128 \\
\hline B32 & 46 & 46 & 49 & 80 & 82 & 118 \\
\hline B41 & 52 & 50 & 47 & 92 & 86 & 33 \\
\hline B42 & 46 & 33 & 62 & 88 & 75 & 76 \\
\hline $\mathrm{B} 51 / \mathrm{Ga}$ & 39 & 31 & - & 80 & 58 & 192 \\
\hline B52 & 47 & 46 & 53 & 78 & 85 & 122 \\
\hline B61 & 44 & 45 & 42 & 91 & 87 & 28 \\
\hline B62 & 44 & 43 & 42 & 73 & 70 & 68 \\
\hline B71 & 30 & 33 & 24 & 64 & 70 & 109 \\
\hline B72 & 37 & 36 & 42 & 66 & 70 & 123 \\
\hline B81 & 37 & 37 & 38 & 105 & 100 & 51 \\
\hline B82 & 35 & 36 & 36 & 92 & 99 & 58 \\
\hline
\end{tabular}

CSI Parameters of B nucleus

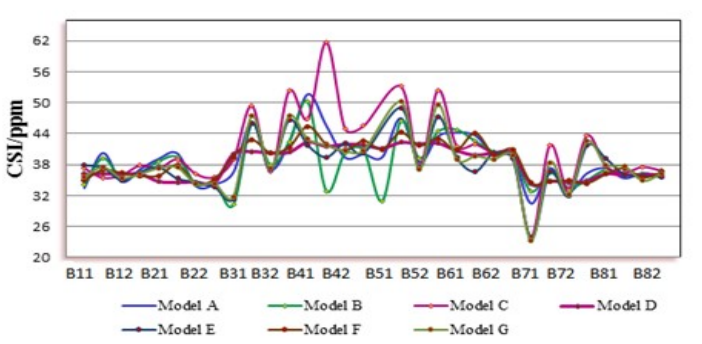

CSI Parameters of $P$ nucleus

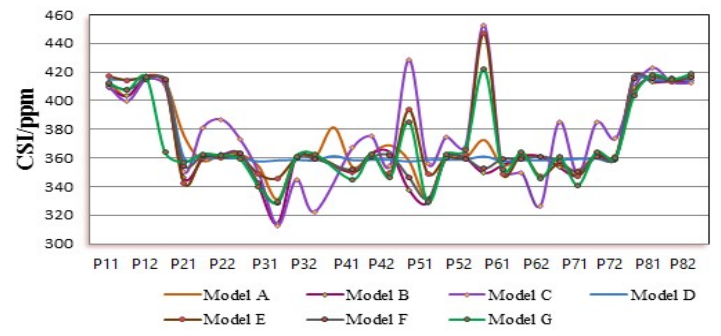

Figure 9. The CSI parameters of $B$ and $P$ nuclei of the $(A-G)$ Models (see figure 1).

showed that when, $\mathrm{N}_{2} \mathrm{O}$ gas is adsorbed on the nonmetal position of nanotube the $\mathrm{N}_{2} \mathrm{O}$ gas was dissociated to $\mathrm{O}$ atom and $\mathrm{N}_{2}$ molecule. The $\mathrm{O}$ atom strongly is adsorbed atop surface of nanotube, the electrical and structural parameters of nanotube changed significantly from original values. On the other hand, gap energy, global hardness, electrophilicity index and other quantum parameters changed significantly. With adsorbing $\mathrm{N}_{2} \mathrm{O}$ gas on the $\mathrm{B}$ site of nanotube (the $\mathrm{D}-\mathrm{G}$ models) the electrical and structure parameters changed slightly from original values. The adsorption energy values of the all the models were negative and all process was exothermic according to thermodynamic approach. The adsorption energy of the $\mathrm{C}$ model was more than that of other models and this model was stable than other models. When, $\mathrm{N}_{2} \mathrm{O}$ gas is adsorbed atop surface of BPNTs in the $\mathrm{A}, \mathrm{B}$ and $\mathrm{C}$ models the global hardness deceased significantly from pure values. On other hand, the electrophilicity index $(\omega)$, electronic chemical potential $(\mu)$, electronegativity $(\chi)$ and global softness $(S)$ of the A, 
Table 4. NMR parameters for adsorption $\mathrm{N}_{2} \mathrm{O}$ on the surface of $(4,4)$ armchair BPNTs (models D - G figure 1).

\begin{tabular}{|c|c|c|c|c|c|c|c|c|}
\hline \multirow{2}{*}{ Nuclei } & \multicolumn{4}{|c|}{ CSI } & \multicolumn{4}{|c|}{ CSA } \\
\hline & Model D & Model E & Model F & Model G & Model D & Model E & Model F & Model G \\
\hline P11 & 415 & 417 & 411 & 413 & 92 & 85 & 96 & 90 \\
\hline P12 & 415 & 414 & 408 & 407 & 57 & 74 & 90 & 98 \\
\hline P21 & 360 & 343 & 355 & 357 & 245 & 242 & 227 & 206 \\
\hline P22 & 360 & 360 & 362 & 363 & 245 & 242 & 224 & 215 \\
\hline P31 & 358 & 349 & 342 & 340 & 89 & 107 & 180 & 155 \\
\hline P32 & 358 & 346 & 329 & 329 & 88 & 128 & 186 & 207 \\
\hline $\mathrm{P} 41 / \mathrm{Si}$ & 361 & 446 & 270 & 236 & 246 & 225 & 158 & 99 \\
\hline P42 & 358 & 350 & 352 & 345 & 249 & 253 & 241 & 245 \\
\hline P51 & 358 & 394 & 346 & 385 & 103 & 144 & 179 & 77 \\
\hline P52 & 359 & 349 & 331 & 329 & 101 & 111 & 183 & 216 \\
\hline P61 & 361 & 447 & 352 & 422 & 237 & 202 & 215 & 209 \\
\hline P62 & 358 & 349 & 360 & 352 & 241 & 247 & 219 & 228 \\
\hline P71 & 359 & 356 & 358 & 360 & 86 & 103 & 152 & 163 \\
\hline P72 & 359 & 347 & 350 & 341 & 82 & 112 & 153 & 174 \\
\hline P81 & 415 & 406 & 416 & 404 & 115 & 97 & 114 & 92 \\
\hline P82 & 414 & 417 & 416 & 418 & 120 & 123 & 124 & 121 \\
\hline B11 & 36 & 38 & 35 & 36 & 141 & 146 & 133 & 123 \\
\hline B12 & 36 & 37 & 37 & 38 & 120 & 127 & 122 & 123 \\
\hline B21 & 35 & 37 & 36 & 37 & 83 & 72 & 33 & 36 \\
\hline B22 & 35 & 35 & 38 & 37 & 83 & 54 & 28 & 24 \\
\hline B31 & 40 & 31 & 40 & 32 & 99 & 103 & 129 & 125 \\
\hline B32 & 40 & 46 & 43 & 47 & 99 & 105 & 108 & 109 \\
\hline B41 & 42 & 42 & 45 & 43 & 66 & 55 & 42 & 31 \\
\hline B42 & 42 & 39 & 42 & 42 & 66 & 34 & 55 & 83 \\
\hline $\mathrm{B} 51 / \mathrm{Ga}$ & 41 & - & 41 & - & 103 & 105 & 141 & 363 \\
\hline B52 & 42 & 49 & 44 & 50 & 102 & 111 & 114 & 117 \\
\hline B61 & 41 & 39 & 41 & 39 & 34 & 31 & 32 & 22 \\
\hline B62 & 40 & 37 & 44 & 40 & 57 & 36 & 36 & 64 \\
\hline B71 & 34 & 24 & 34 & 23 & 99 & 99 & 116 & 105 \\
\hline B72 & 35 & 37 & 35 & 38 & 100 & 36 & 122 & 123 \\
\hline B81 & 36 & 39 & 36 & 38 & 69 & 65 & 62 & 59 \\
\hline B82 & 36 & 36 & 37 & 38 & 65 & 41 & 64 & 68 \\
\hline
\end{tabular}

$\mathrm{B}$ and $\mathrm{C}$ models increased significantly from pure BPNTs. The results revealed that the CSI values of P22, P51 and P61 nuclei for the B, C and G model were: C model $>$ B model $>$ G model.

\section{References}

1. A S Tarendash, Let's review: chemistry, the physical setting, Barron's Educational Series (2004).

2. M Iwamotoand H Hamada, Catal. Today 10 (1991) 57.

3. F Kaptein, J Rodriguez-Mirasol, and J A Moulijn, App. Cataly B 9 (1996) 25.

4. G Delahay, M Mauvezin, B Coq, and S Kieger, J. Cataly 202 (2001) 156.

5. B Coq, M Mauvezin, G Delahay, J B Butet, and S Kieger, App. Cataly B 27 (2000)193.

6. B Moden, P Da Costa, B Fonfe, D Ki Lee, and E Iglesia, J. Cataly 209 (2002) 75.

7. A Martinez, A Goursot, B Coq, and G Delahay, $J$. Phys. Chem. B 108 (2004) 8823.

\section{Acknowledgment}

The authors thank the Centre of computational nano of Malayer Universities for supporting this research.
8. A R Ravishankara, J S Daniel, and R W Portmann, Science 326 (2009) 23.

9. M T Baei, A Soltani, A V Moradi, and E Tazikeh Lemeski, Com. Theo. Chem. 970 (2011) 30.

10. M T Baei and A Soltani, A V Moradi, M Moghimi, Monatsh Chem. 142 (2011) 573.

11. A Soltani, M Ramezani Taghartapeh, E Tazikeh Lemeski, M Abroudi, and H Mig, Superlatt Microstruct 58 (2013)178.

12. X Solans-Monfort, M Sodupe, and V Branchadell, Chem. Phys. Lett. 368 (2003) 42.

13. M Mirzaei, Z Phys. Chem. 223 (2005) 815.

14. M T Baei, A Varasteh Moradi, P Torabi, and M Moghimi, Monatsh Chem. 142 (2011) 1097. 
15. M T Baei, A Ahmadi Peyghan, and M Moghimi, Monatsh Chem. 143 (2012) 1627.

16. M T Baei, Monatsh Chem. 143 (2012) 881.

17. M Mirzaei, J. Mol. Model 17 (2011) 89.

18. A Ahmadi Peyghan M T, Baei, M Moghimi, and S Hashemian, J. Clust. Sci 24 (2013) 49.

19. M T Baei, A Varasteh Moradi, P Torabi, and M Moghimi, Monatsh Chem 143 (2012) 37.

20. K Li, W Wang, D Cao, Sens Actuat B Chem. 159 (2011)171.

21. M Rezaei-Sameti, Physica B 407 (2012)3717.

22. M Rezaei-Sameti, Physica E 44 (2012)1770.

23. M Rezaei-Sameti and S Yaghobi, Comp. Condense Matt. 3 (2015) 21.

24. M Rezaei-Sameti, Physica B 407 (2012) 22.
25. M Rezaei-Sameti, E A Dadfar, Iran. J. Phys. Res. 15 (2015) 41.

26. M J Frisch, et al., GAUSSIAN 03 (2003).

27. P K Chattaraj, U Sarkar, and D R Roy, Chem. Rev. 106 (2006) 2065.

28. K K Hazarika, N C Baruah, and R C Deka, Struct. Chem. 20 (2009)1079.

29. R G Parr, L Szentpaly, and S Liu, J. Am. Chem. Soc. 121(1999) 1922.

30. C Tabtimsai, S Keawwangchai, N Nunthaboot, V Ruangpornvisuti,and B Wanno, J Mol Model 18 (2012) 3941.

31. A E Reed, L A Curtiss, F Weinhold, Chem. Rev. 88 (1988) 899. 